\title{
Effects of Inhibitors of RNA and Protein Synthesis on Bean Hypocotyl Hook Opening and their Implications Regarding Phytochrome Action
}

\author{
B. G. KaNG and P. M. RAY \\ Department of Botany, University of Michigan, Ann Arbor
}

Received January 29/April 7, 1969

\begin{abstract}
Summary. Inhibitors of protein and RNA synthesis (cycloheximide, puromycin, chloramphenicol, and actinomycin D), as well as $\mathrm{Co}^{++}$, induce opening of the hypocotyl hook of bean seedlings during the early stage of the opening period both in the darkness and red light. The response is transitory, however, complete straightening of a hook can not be achieved in the presence of these agents. These agents abolish the response of hooks to red illumination. They also block the suppression of hook opening caused by IAA and ethylene. The response and sensitivity to GA are not affected by the inhibitors. Inhibitors of DNA synthesis (FUDR and mitomycin C) have no effect on hook opening. It appears that in this growth response RNA and protein synthesis are more immediately involved in ethylene action than they are in the cell elongation process or the action of GA thereon.

The results indicate that phytochrome does not induce hook opening simply by activating genes whose products directly promote growth. It is suggested that the regulation of ethylene formation by light and auxins may be exerted by way of influences on tissue levels of phenolic inhibitors of ethylene biosynthesis.
\end{abstract}

\section{Introduction, Material and Methods}

The problem of the primary action of phytochrome has been disputed in the last few years. MoHr $(1966 \mathrm{a}, \mathrm{b})$ postulated that in what he termed "positive" photomorphogenic responses the active form of phytochrome $\left(P_{730}\right)$ acts through differential gene activation. The principal evidence for this view is the suppression of such photoresponses by inhibitors of RNA and protein synthesis (SCHOPFER, 1967a; LANGE et al., 1967; and literature there cited). HendRICKS and BoRTHWICK (1967), on the other hand, proposed that phytochrome acts by affecting membrane permeability. This idea was based primarily on the existence of certain phytochrome responses that seemed too rapid to be explainable on an epigenetic basis; and on the possible location of phytochrome in or near the plasma membrane (Fondevilute et al., 1967; TANADA, 1968; cf. BeWley et al., 1968).

The present report deals with the action of inhibitors of nucleic acid and protein synthesis on the response of bean hypocotyl hook tissue to red light and to growth regulators; this photoresponse has been classified 
by MoHr (1966a, b) as "positive". It will be shown that, contrary to previously published conclusions (CARR and REID, 1966; SCHOPFER, 1967a), phytochrome probably does not act on this system simply by activating genes that promote growth. It most likely acts indirectly, by inhibiting ethylene synthesis, by a mechanism that may involve either enzyme repression, enzyme induction, or an action (such as on membranes) that is not at the level of gene function at all.

Plant material and methods of experimentation are described in previous publications (KANG and RAY, $1969 \mathrm{a}, \mathrm{b}$ ).

\section{Results}

All the metabolic inhibitors tested had essentially the same effect on hook opening as shown in Fig. 1. The degree of opening measured after $20 \mathrm{hr}$ in red light was reduced by these inhibitors. In the darkness, however, considerable hook opening was induced by the inhibitors at concentrations that inhibit protein or RNA synthesis in plant tissues and that reduced hook opening in the light. The effects of cycloheximide and puromycin appear to be stronger than those of chloramphenicol and actinomycin $\mathrm{D}$.

Table 1. Effects of inhibitors on incorporation of ${ }^{14} \mathrm{C}$-leucine into hook tissue protein

\begin{tabular}{ll}
\hline Treatment & $\begin{array}{l}{ }^{14} \mathrm{C} \text { incorporation } \\
\text { (\% of control) }\end{array}$ \\
\hline Cycloheximide $(10 \mu \mathrm{g} / \mathrm{ml})$ & 14 \\
Puromycin $\left(10^{-3} \mathrm{M}\right)$ & 74 \\
Chloramphenicol $\left(5 \times 10^{-3} \mathrm{M}\right)$ & 78 \\
Actinomycin D $(25 \mu \mathrm{g} / \mathrm{ml})$ & 91 \\
$\mathrm{CoCl}_{2}\left(10^{-3} \mathrm{M}\right)$ & 97 \\
$\mathrm{IAA}(1 \mu \mathrm{g} / \mathrm{ml})$ & 90 \\
\hline
\end{tabular}

10 hook segments were incubated $6 \mathrm{hr}$ in $5 \mathrm{ml}$ of test solution containing $1 \mu \mathrm{C}$ of L-leucine-119 $(200 \mathrm{mC} /$ mmole) followed by $18 \mathrm{hr}$ in the same test solution without ${ }^{14} \mathrm{C}$-leucine. Tissue was extracted and its protein precipitated with trichloroacetic acid and washed by the method of Noonén and THIMañ (1965), then counted on a planchet at about $33 \%$ efficiency. Figures are the average of 4 experiments, except for puromycin and actinomycin ( 2 experiments).

The data given in Table 1 indicate that the effect of cycloheximide on incorporation of ${ }^{14} \mathrm{C}$-leucine into protein by bean hook tissue is stronger than the effect of puromycin and of chloramphenicol. Actinomycin, as expected, had little effect on incorporation of leucine into protein. Inhibition of RNA synthesis by actinomycin and of protein synthesis by puromycin and cycloheximide in bean seedling tissue has been reported previously (ABEwES and Holm, 1966; WALTON, 1966). 


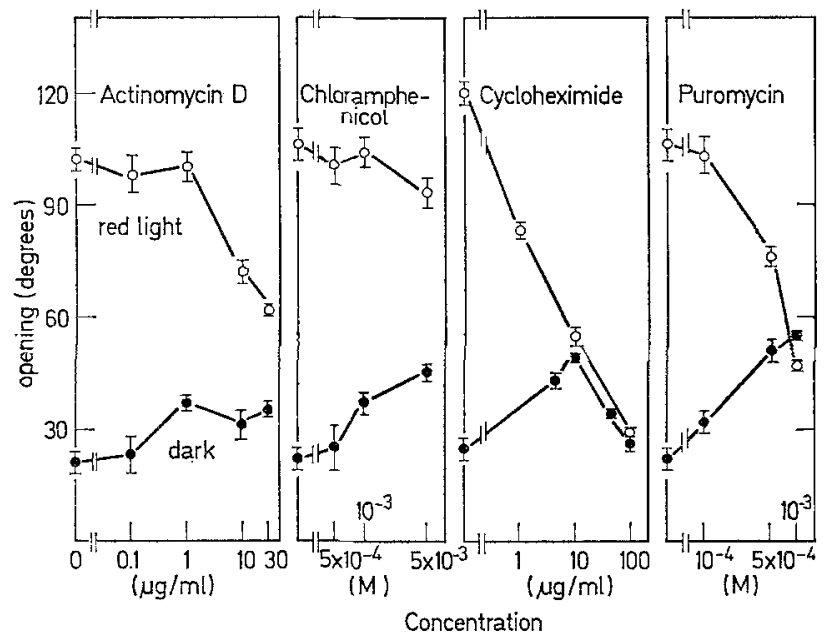

Fig. 1. Effects of antibiotics on hook opening

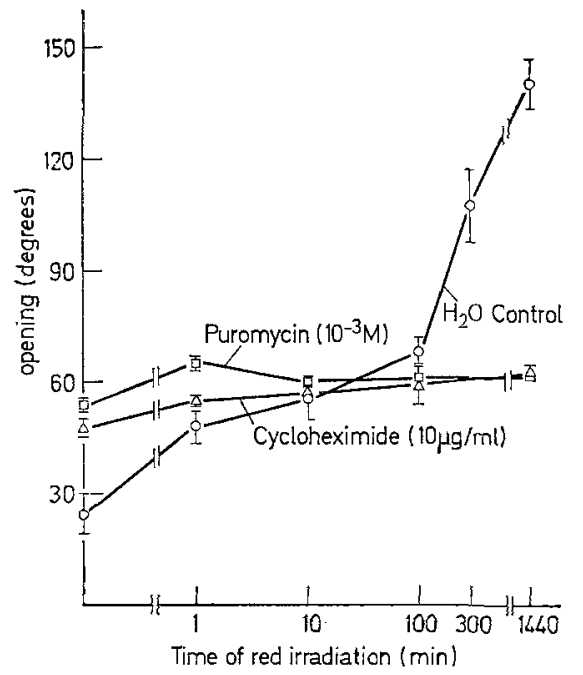

Fig. 2

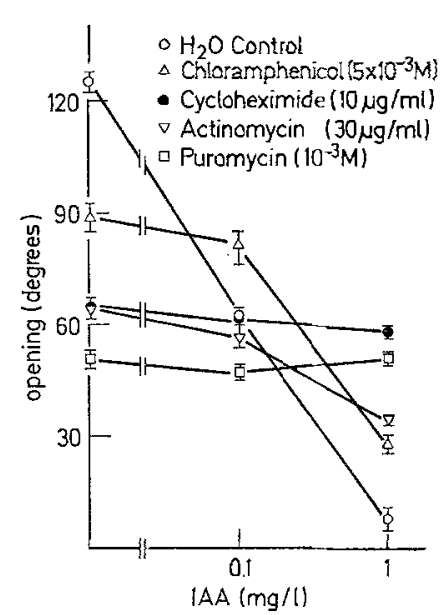

Fig 3

Fig. 2. Response to red light dosage of hooks treated with antibiotics

Fig. 3. Response to IAA of hooks treated with antibiotics in red light

Fig. 2 illustrates the response to red light dosage of hooks treated with the antibiotics as compared with that of non-treated hooks. Normally, the degree of opening increases as the dosage of red light is increased, but cycloheximide- and puromycin-treated hooks show a lack of this response to red light, the opening remaining constant with all dosages of red light. 


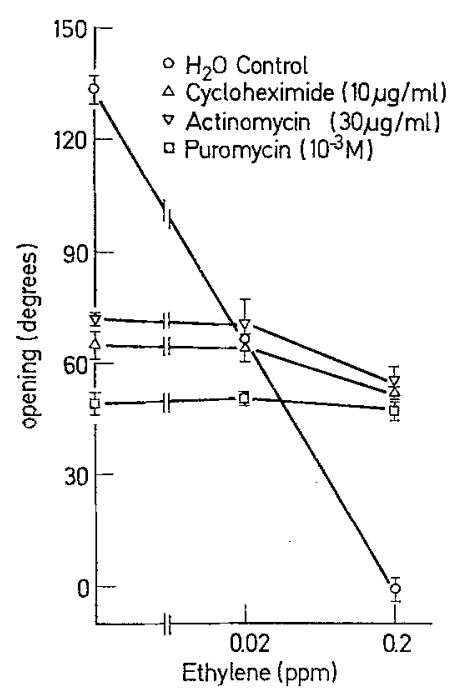

Fig. 4

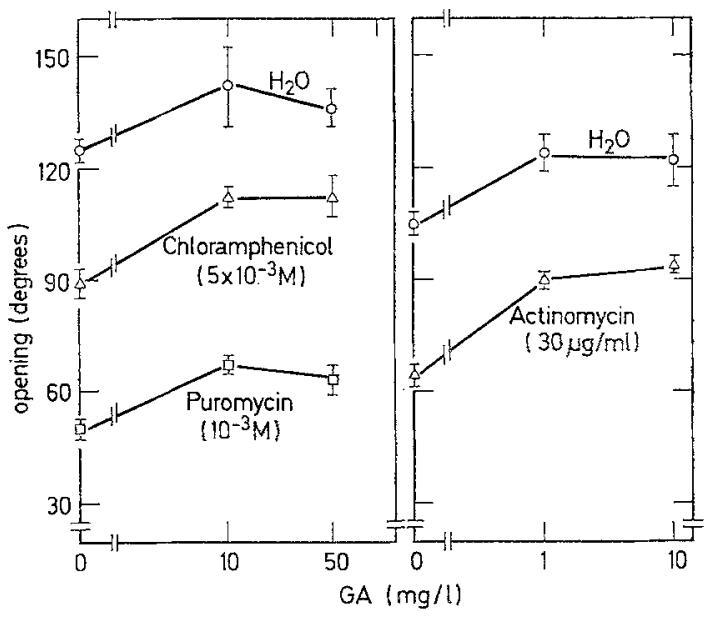

Fig. 5

Fig. 4. Response to ethylene of hooks treated with antibiotics in red light

Fig. 5. Response to GA of hooks treated with antibiotics in red light

As shown in Fig. 3, cycloheximide and puromycin completely block IAA-inhibition of hook opening in red light; the opening in red light of antibiotic-treated hooks is unaffected by 0.1 and $1 \mathrm{mg} / 1$ of IAA, which inhibit the opening of non-treated hooks approximately 50 and $100 \%$, respectively.

Fig. 4 shows that cycloheximide, puromycin, and actinomycin $\mathrm{D}$ also prevent the inhibition of hook opening by ethylene.

The action of GA on hook opening is not affected by the inhibitors. Opening of inhibitor-treated hooks is promoted by GA to about the same extent as that of non-treated hooks (Fig. 5).

In Fig. 6, time course curves of opening in the presence and absence of cycloheximide are given. They indicate that during the early part of the opening course, cycloheximide maximally promotes hook opening regardless of other factors such as red light and IAA. However after about $10 \mathrm{hr}$ opening slows down markedly in the presence of cycloheximide. Similar results were obtained with puromycin.

Inhibitors of DNA synthesis (NITSAN and LANG, 1965; BopP, 1966) were used to test whether DNA synthesis might be invoved in the hook opening response. Fig. 7 shows that 5-fluorodeoxyuridine (FUDR) and mitomycin $\mathrm{C}$ do not have any significant effect on hook opening. FUDR, furthermore, did not affect the ability of GA to promote hook opening (Table 2). 


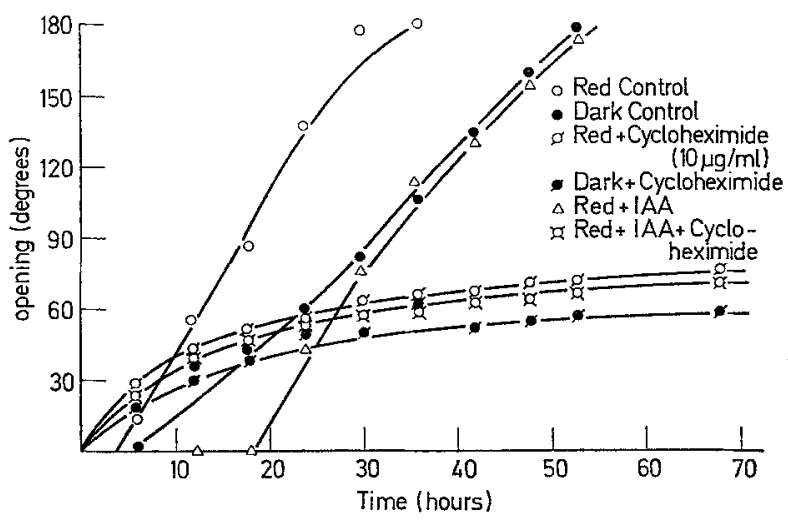

Fig. 6. Time course of opening process of hooks treated with cycloheximide and IAA

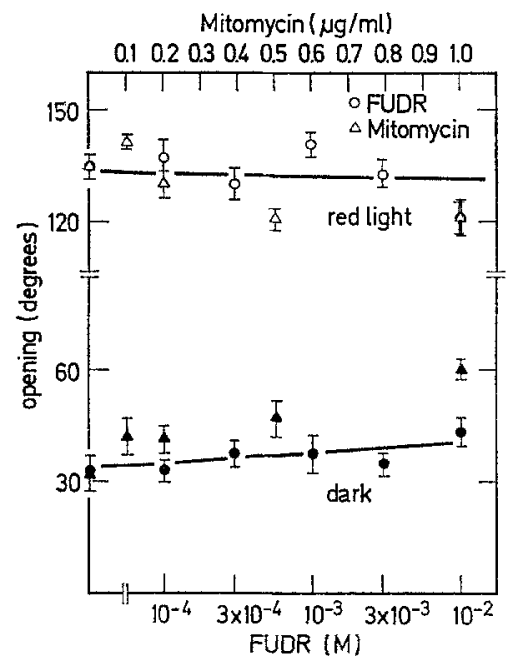

Fig. 7. Effects of FUDR and mitomycin $\mathrm{C}$ on hook opening

Table 2. Effects of FUDR and 5-fluorouracil (FU) on the hooks treated with GA and $I A A$

\begin{tabular}{lrrr}
\hline Hormone & \multicolumn{3}{l}{ Hook opening, degrees ${ }^{\mathrm{a}}$} \\
\cline { 2 - 4 } & $\mathrm{H}_{2} \mathrm{O}$ & $\begin{array}{r}\text { FUDR } \\
\left(5 \times 10^{-2} \mathrm{M}\right)\end{array}$ & $\begin{array}{l}\text { FU } \\
\end{array}$ \\
& & $\left(5 \times 10^{-2} \mathrm{M}\right)$ \\
\hline None & $117 \pm 3.2$ & $120 \pm 1.9$ & $120 \pm 1.9$ \\
GA $(10 \mathrm{mg} / \mathrm{l})$ & $48 \pm 2.6$ & $148 \pm 2.9$ & $146 \pm 2.1$ \\
IAA $(0.1 \mathrm{mg} / \mathrm{l})$ & $35 \pm 3.8$ & $41 \pm 3.7$ \\
\hline
\end{tabular}

a Opening in red light. 


\section{Diseussion}

The effect of auxin on light-induced hook opening is blocked by actinomycin D, puromycin, and cycloheximide, in conformity with the widespread view that auxin action depends upon $m-R N A$ and protein synthesis (KwY, 1969). However, the effect of auxin on growth in this response is an inhibitory one. It was shown that this inhibition is attributable largely to the fact that auxin. induces formation of ethylene by the tissue and ethylene inhibits hook opening (KANG et al., 1967; KANG and RAY, $1969 \mathrm{~b}$ ). The induction, by auxin, of ethylene formation has been found to be sensitive to inhibitors of RNA and protein synthesis (ABELES, 1966); and cycloheximide was found to block ethylene formation by bean tissue (KANG et al., 1967).

Inhibition of auxin action on hook opening by cycloheximide, puromycin, and actinomycin D might suggest that auxin acts by inducing the formation of enzymes involved in the biosynthesis of ethylene. However, it was shown above that the inhibitors of RNA and protein synthesis prevent inhibition of hook opening by ethylene, indicating that the inhibitory action of ethylene itself depends upon protein synthesis, as was reported for the action of ethylene on leaf abscission (ABELES and Holm, 1966; Aberes, 1968) and on pea fruit ripening (Frenkel et al., 1968). Therefore, the blocking, by the antibiotics, of the action of auxin on hook opening was probably due to prevention of ethylene action by the antibiotics and cannot be considered evidence for a direct action of auxin at the nucleic acid or protein synthesis level in this system.

GA exerts an effect on hook opening opposite to that of ethylene, as reported in certain other plant responses (SCOTT and LEOPOLD, 1967). It was observed above that antibiotic treatments that substantially inhibit hook opening, and that abolish the effect of auxin, ethylene and red light on it, do not prevent the promotion of hook opening by GA. This support the previous conclusion (KANG and RAY, 1969 b) that the effect of GA on hook opening is independent of ethylene. It also indicates, contrary to the widely held view that GA acts at the level of gene function (cf. literature reviewed by $\mathrm{KNY}$, 1969), that the promotive effect of GA on the present system may be independent of RNA and protein synthesis, as suggested recently for certain other GA effects by Poltiard and StNGH (1968).

NAKAMURA and TAKaHASHI (1968) found a partial inhibition of the (much larger than in the present system) gibberellin-induced growth of pea epicotyl hooks by chloramphenicol and mitomycin $\mathrm{C}$, and concluded that nucleic acid and protein synthesis is necessary for that response. We obtained, in contrast, no inhibition by mitomycin $\mathrm{C}$ or another inhibitor of DNA synthesis (FUDR), either of light-induced bean hook opening or of its promotion by GA. 
A considerable amount of investigation substantiates that nucleic acid or protein synthesis is required for growth of plant tissues (KEY, 1969). The failure of complete opening in the presence of actinomycin D, cycloheximide and puromycin is most likely an indication of an inhibitory effect of these antibiotics on the synthesis of RNA and proteins necessary for elongation of cells on the inner side of this hook. CARR and REID (1966) and ScHOPFER (1967a), who obtained similar inhibitions, by some of these agents, of photoinduced hook opening in bean and pea seedlings, and in mustard seedlings respectively, interpreted them as evidence that phytochrome promotes hook opening by activating genes for specific protein synthesis, in conformity with MoHR's (1966a, b; LANGE et al., 1967) concept of a "positive" photoresponse. Because of the known action of these inhibitors upon growth in general, the simple inference that in this system they are specifically blocking phytochrome action is dubious. However, we show here that they prevent the promotion of hook opening by red light under circumstances in which hook opening, and therefore cell growth, have not been completely prevented. Therefore, these inhibitors do at least seem to interrupt the chain between phytochrome and the growth process in hook cells.

This interruption is entirely explicable on the basis that these inhibitors prevent the inhibitory effect of ethylene on hook opening: if light promotes hook opening, as was deduced earlier (KANG and RAY, 1969b), by suppressing ethylene production and by promoting $\mathrm{CO}_{2}$ production which antagonizes ethylene action, then it must be expected that if ethylene action is prevented, light will have no effect. This should be so whether or not $P_{\mathbf{7 3 0}}$ has any direct influence on gene activity.

An especially intriguing observation is that inhibitors of protein synthesis induce rapid hook opening in the dark during the first few hours of treatment. ScHOPFER (1967a) reported that puromycin induces hook opening in mustard seedlings, in the dark, in the same concentration range as it inhibits light-induced opening. His method did not permit him to follow the time course of this effect properly but the reported results seem strikingly similar to our observations on the bean hypocotyl hook with puromycin, cycloheximide and chloramphenicol. ScHOPFER (1967 a) was at a loss to interpret this in terms of MoHR's view of hypocotyl hook opening as a "positive" photoresponse dependent upon gene activation by $P_{730}$. As in the present case, actinomycin $D$ had a small but definite inductive effect on opening in the dark (SCHOPFER, 1967a).

These observations actually suggest the opposite possibility that hook opening might be a "negative" photoresponse (MoнR, 1966a, b), which SCHOPFER $(\mathbf{1 9 6 7} \mathrm{b})$ held to be due to differential gene repression by $\mathbf{P}_{730}$ and which should therefore be mimicked by inhibitors of RNA and protein synthesis. It might be proposed that $P_{730}$ acts on hypocotyl 
hook opening by repressing formation of enzymes responsible for ethylene production. However, this hypothesis is rendered gratuitous by the fact that the inhibitors block the ethylene action, since this latter effect is sufficient to explain the early induction of hook opening by the inhibitors. From the time course it appears that the action of the inhibitors upon the effectiveness of ethylene is relatively rapid, whereas the growth process itself is only gradually suppressed by the antibiotics, as has been observed in a number of growing systems (cf. KEX, 1969). This implies that proteins specific to the elongation process of hook cells turn over relatively slowly compared to some that are involved specifically in the inhibition by ethylene, or more likely that ethylene inhibition depends upon continual synthesis of new protein.

Regarding the means by which $\mathrm{P}_{730}$ influences ethylene formation one possibility seems particularly attractive. The known peroxidase systems that catalyze $\mathrm{C}_{2} \mathrm{H}_{4}$ formation are, like IAA oxidase, affected profoundly by cofactors and inhibitors of a phenolic nature (YANG, 1967; MAPSON and MEAD, 1968). There is a great deal of evidence for photoinduction of increases in phenolic compounds and their relatives such as anthocyanins; in a number of instances this effect is ascribable to induction of phenylalanine ammonia-lyase (ZJCKER, 1968; ENGELSMA, 1968; and literature there cited). These effects possess a timing rather similar to the induction of hypocotyl hook opening in response to light. It may be suggested that $\mathbf{P}_{\mathbf{7 3 0}}$-induced accumulation of polyphenolic inhibitors suppresses ethylene production and thereby causes hook opening. It is apparent that auxin could promote ethylene production by also affecting the phenolic system. This hypothesis has special appeal in the case of pea shoot tissue, whose ethylene production is, like that of the bean hook, inhibited by red light (GoEscre et al., 1967) and promoted by auxin (Burg and BuRg, 1966). Light elevates dramatically (BотTомLEY et al., 1966) and auxin depresses (BoLx, 1965) the levels of polyphenolic inhibitors, as required to explain their effects on ethylene production by the foregoing hypothesis. And in this material ATTRIDGE and SMITH (1967) have demonstrated a phytochrome-induced rise of phenylalanine ammonia-lyase activity whose time-course closely resembles those for changes in polyphenol content and in ethylene production.

The hypothesis that $P_{730}$ affects ethylene production by inducing enzymes for polyphenol synthesis would place hook opening in the category of a "positive" photoresponse, but one in which the gene regulation is rather distantly related to the developmental consequence. It is obvious that $P_{730}$ could, on the other hand, exert an effect upon the phenolic system and thereby on ethylene output by a route other than enzyme induction. WALTON (1968) found no effect of light on the formation of phenylalanine ammonia-lyase in young bean seedlings or seedling 
axes; however, he did not investigate that part of the seedlings (the hook) whose ethylene output is affected by light.

These ideas suggest extensive possibilities for further investigation of the nature of phytochrome regulation of growth in this system.

\section{References}

Abeles, F. B.: Auxin stimulation of ethylene evolution. Plant Physiol. 41, 585-588 (1966).

- Role of RNA and protein synthesis in abscission. Plant Physiol. 43, 1577-1586 (1968).

-, and R. E. Holm : Enhancement of RNA synthesis and abscission by ethylene. Plant Physiol. 41, 1377-1342 (1966).

AtrtRIDGe, H. T., and H. Smith: A phytochrome-mediated increase in the level of phenylalanine ammonia-lyase activity in the terminal buds of Pisum sativum. Biochim. Biophys. Acta (Amst.) 148, 805-807 (1967).

BewLeY, J. D., M. NEGBI, and M. BLACK: Immediate phytochrome action in lettuce seeds and its interaction with gibberellins and other germination promoters. Planta (Berl.) 78, 351-357 (1968).

BoLt, W. G.: On the claimed adaptive nature of IAA oxidase and an effect of green light on IAA oxidase activity. Canad. J. Bot. 43, 885-892 (1965).

Bopr, M.: Die Wirkung von Nukleinsäurehemmstoffen auf die Morphogenese von Pflanzen. Biol. Rundschau 4, 25-36 (1966).

BotтomLey, W., H. Sмiтt, and A. W. Galston : The effect of light on the synthesis of kaempferol and quercitin complexes. Phytochem. 5, 117-123 (1966).

BurG, S. P., and E. A. BURG: The interaction between auxin and ethylene and its role in plant growth. Proc. Nat. Acad. Sei. (Wash.) 55, 262-269 (1966).

CARR, D. J., and D. M. RerD : Actinomycin-D inhibition of phytochrome-mediated. responses. Planta (Berl.) 69, 70-78 (1966).

Engetsma, G.: Photoinduction of phenylalanine deaminase in gherkin seedlings. III. Effects of excision and irradiation on enzyme development in hypocotyl segments. Planta (Berl.) 82, 355-368 (1968).

Fondevilue, J. C., M. J. Sohnerder, H. A. Borthwick, and S. B. Hendricks: Photocontrol of Mimosa pudica L. leaf movement. Planta (Berl.) 75, 228-238 (1967).

Frenkel, C., I. KletN, and D. R. Dilley : Protein synthesis in relation to ripening of pome fruits. Plant Physiol. 43, 1146-1153 (1968).

Goeschl, J. D., H. K. Pratt, and B. A. Bonner: An effect of light on the production of ethylene and the growth of the plumular portion of etiolated pea seedlings. Plant Physiol. 42, 1077-1080 (1967).

Hendricks, S. B., and H. A. BoRTHwick: The function of phytochrome in regulation of plant growth. Proc. Nat. Acad. Sci. (Wash.) 58, 2125-2130 (1967).

KANG, B. G., and P. M. RAY : Role of growth regulators in the bean hypocotyl hook opening response. Planta (Berl.) 87, 193-205 (1969a).

- - Ethylene and carbon dioxide as mediators in the response of the bean hypocotyl hook to light and auxins. Planta (Berl.) 87, 206-216 (1969b).

- C. S. Yocum, S. P. Bura, and P. M. RaY: Ethylene and carbon dioxide; Mediation of hypocotyl hook-opening response. Science 156, 958-959 (1967).

KEY, J. L. : RNA and hormone action. Ann. Rev. Plant Physiol. 20 (in press) (1969).

15 Planta (Berl.), Bd. 87 
Lavge, H., I. Brenger u. H. Mohr: Eine neue Beweisführung für die Hypothese einer differentiellen Genaktivierung durch Phytochrom 730. Planta (Berl.) 76, 359-366 (1967).

MAPSON, L. W., and A. Mran: Biosynthesis of ethylene. Dual nature of cofactor required for the enzymic production of ethylene from methional. Biochem. J. $108,875-881(1968)$.

MoнR, H.: Differential gene activations as a mode of action of phytochrome 730 . Photochem. Photobiol. 5, 469-482 (1966a).

- Untersuchungen zur phytochrominduzierten Photomorphogenese des Senfkeimlings (Sinapis alba L.). Z. Pflanzenphysiol. 54, 63-83 (1966 b).

Nakamura, T., and N. TAKaHASHT: Relationship between gibberellic acid-induced growth and nucleic acid and protein metabolism in plumular hook section of etiolated pea seedling. Bot. Mag. (Tokyo) 81, 127-134 (1968).

Nitsan, J., and A. LaNG: Inhibition of cell division and cell elongation in higher plants by inhibitors of DNA synthesis. Develop. Biol. 12, 358-379 (1965).

NoodÉN, L. D., and K. V. ThIMANN: Inhibition of protein synthesis and of auxininduced growth by chloramphenicol. Plant Physiol. 40, 193-201 (1965).

Pollard, C. J., and B. N. Srngh: Early effects of gibberellic acid on barley aleurone layers. Biochem. Biophys. Res. Commun. 33, 321-326 (1968).

SCHOPFER, P.: Die Hemmung der phytochrominduzierten Photomorphogenese ("positive" Photomorphosen) des Senfkeimlings (Sinapis alba L.) durch Actinomycin D und Puromycin. Planta (Berl.) 72, 297-305 (1967a).

- Der Einfluß von Actinomycin D und Puromycin auf die phytochrominduzierte Wachstumshemmung des Hypokotyls beim Senfkeimling (Sinapis alba L.). Planta (Berl.) 72, 306-320 (1967b).

ScotT, P. C., and A. C. LEOPOLD: Opposing effects of gibberellin and ethylene. Plant Physiol. 42, 1021-1022 (1967).

TANada, T.: A rapid photoreversible response by barley root tips in the presence of 3-indoleacetic acid. Proc. Nat. Acad. Sci. (Wash.) 59, 376-380 (1968).

WaLton, D. C.: Germination of Phaseolus vulgaris. I. Resumption of axis growth. Plant Physiol. 41, 298-302 (1966).

- L-Phenylalanine ammonia-lyase activity during germination of Phaseolus vulgaris. Plant Physiol. 48, 1120-1124 (1968).

$Y_{A N C}$, S. F.: Biosynthests of ethylene. Ethylene formation from methional by horseradish peroxidase. Arch. Bioehem. Biophys. 128, $481-487\{1967\}$.

ZUCKRR, M. : Sequential induction of phenylalanine ammonia-lyase and a lyaseinartivating system in potato tuber discs. Plant Physiol. 43, 365-374 (1968).

Dr. BIN G. KANG

MSU/AEC Plant Research Laboratory

Michigan State University

East Lansing, Michigan 48823, USA
Dr. Peter M. Ray

Department of Biological Sciences

Stanford University

Stanford, California 94305, USA 